\title{
Transverse Sinus Stenosis Is the Most Sensitive MR Imaging Correlate of Idiopathic Intracranial Hypertension
}

\author{
DP.P. Morris, (DD.F. Black, (D). Port, and (D) N. Campeau
}

\begin{abstract}
BACKGROUND AND PURPOSE: Patients with idiopathic intracranial hypertension have transverse sinus stenosis on gadolinium-bolused MRV, but other MR imaging signs are less consistently seen. Our aim was to demonstrate that transverse sinus stenosis could be identified on conventional MR imaging, and this identification would allow improved diagnostic sensitivity to this condition.
\end{abstract}

MATERIALS AND METHODS: MR imaging and MRV images from 63 patients with idiopathic intracranial hypertension and 96 controls were reviewed by using 3 independent procedures. MRV images were graded for the presence and degree of stenosis of the transverse sinus. Postgadolinium coronal Tl-weighted sequences were evaluated independent of MRV. The dimensions of the proximal and distal transverse sinus were measured from the MRV examinations, and the cross-sectional area of the transverse sinus was calculated. Correlation among the 3 modes of evaluation of the transverse sinus was conducted by using Wilcoxon/Kruskal-Wallis, Pearson, and Spearman $\rho$ nonparametric statistical techniques.

RESULTS: Transverse sinus stenosis was identified bilaterally on MRV in 94\% of patients with idiopathic intracranial hypertension and in $3 \%$ of controls. On coronal T1 postgadolinium MR images, transverse sinus stenosis was identified in $83 \%$ of patients with idiopathic intracranial hypertension and $7 \%$ of controls. Previously described MR imaging signs of intracranial hypertension were identified in $8 \%-61 \%$ of patients with idiopathic intracranial hypertension. Correlation among the 3 modes of evaluation was highly significant $(P<.0001)$.

CONCLUSIONS: Even without the assistance of an MRV sequence, neuroradiologists can validly identify bilateral transverse sinus stenosis in patients with intracranial hypertension more reliably than other previously described MR imaging findings in this condition. We conclude that transverse sinus stenosis is the most useful and sensitive imaging indicator of this disease state.

ABBREVIATIONS: $॥ \mathrm{H}=$ idiopathic intracranial hypertension; $\mathrm{TS}=$ transverse sinus

$\mathbf{P}$ rimary idiopathic intracranial hypertension (IIH), alternatively known as pseudotumor cerebri, is a little-understood condition characterized by unexplained elevation of intracranial pressure. The diagnosis is established by the Modified Dandy Criteria, which, in essence, means an opening pressure at lumbar puncture of $>250 \mathrm{~mm}$ of water in adults and $>280 \mathrm{~mm}$ in children, with no definable etiology. ${ }^{1}$ The condition is known to be more prevalent in young adult women, especially those with an elevated body mass index, ${ }^{2,3}$ older men with obstructive sleep apnea, ${ }^{4-7}$ and patients with a variety of endocrine conditions. ${ }^{4,8}$ It is associated with the use of several medications, most notably vitamin A derivatives and tetracycline antibiotics. ${ }^{9,10}$ Headache is

Received September 12, 2016; accepted after revision November 2.

From the Department of Radiology, Mayo Clinic, Rochester, Minnesota.

Please address correspondence to Pearse Morris, MB, BCh, Department of Radiology,

Mayo Clinic, 200 First Street SW, Rochester, MN 55905; e-mail: morris.ppearse@mayo. edu

http://dx.doi.org/10.3174/ajnr.A5055 the most consistent symptom experienced by patients, though back and shoulder discomfort can be reported too. Papilledema progressing to variable degrees of transient or permanent visual loss is a familiar but not necessarily a sine qua non manifestation. Idiopathic intracranial hypertension in children can present with features less commonly seen in adults, most particularly signs of intracranial mass effect, including cranial nerve deficits, most notably in cranial nerve VI. ${ }^{11}$ The prolonged debilitation and suffering associated with this condition can be substantial. Symptoms may overlap those seen in migraine, and misdiagnosis creates delays that may have substantial comorbidities. The most concerning complication of untreated or treatment-resistant IIH is visual loss, which can progress rapidly and become irreversible once the patient becomes symptomatic. Therefore, it is important to recognize and diagnose this condition clinically and on imaging studies as early as possible.

Several brain MR imaging findings have been associated with the diagnosis of idiopathic intracranial hypertension. These in- 
clude an appearance of an empty sella ( $>50 \%$ vacancy of the sella with a concave upper surface of the pituitary gland), optic nerve sheath dilation, vascular distension and protrusion of the optic papillae with advanced papilledema, "slit ventricles," and a bright spot at the optic nerve head on diffusion-weighted imaging. However, published sensitivity and prevalence of these findings are inconsistent, ranging between $6 \%$ and $66 \% .{ }^{12}$ When a gadolinium-bolused MRV sequence is available, bilateral transverse sinus (TS) stenosis of $>50 \%$ degree is seen in $93 \%$ of patients with IIH, suggesting that this is the most sensitive imaging characteristic of this condition. ${ }^{13,14}$ However, unless the specific diagnosis of IIH has been canvassed in advance and the imaging sequences have been protocoled accordingly, in most instances, the reading neuroradiologist will not have an MRV sequence available to assist in making this diagnosis. Therefore, it is very likely that in a substantial proportion of cases of $\mathrm{IIH}$, only a conventional set of MR images will be obtained and the diagnosis is likely to be missed.

The purpose of this study was to attempt to define the sensitivity with which neuroradiologists might be capable of perceiving signs of TS stenosis on non-MRV imaging, specifically by focusing on the coronal postgadolinium T1-weighted images. In the authors' experience, TS stenosis was identifiable on coronal T1 with gadolinium contrast imaging in a high proportion of patients with $\mathrm{IIH}$, and we conjectured that it might be possible to improve one's sensitivity to this disease state by emphasizing the utility of this sequence, even when an MRV examination has not been performed.

\section{MATERIALS AND METHODS \\ Subjects}

We conducted a retrospective study with institutional review board approval of images acquired during a 5-year period (20102015) in 63 adult and teenage patients in whom the diagnosis of IIH was established according to the Modified Dandy Criteria. Patients were identified by searching key words in the electronic medical records. Only patients who had available images from both a gadolinium-bolused MRV examination and a pre-/postgadolinium MR imaging examination during the period of review were included. Patients who had already undergone a therapeutic shunting procedure, such as a ventriculoperitoneal shunt or lumbar-peritoneal shunt were excluded from the study. Ongoing or already initiated medical therapy did not preclude inclusion in the study. Electronic medical records were reviewed for clinical parameters such as symptom profile, age, weight, body mass index, opening pressure at lumbar puncture, visual symptoms, and duration of symptoms.

A control group of 96 patients without IIH was identified from a consecutive list of MR imaging/MRV studies performed during the same period (Table 1). Inclusion criteria were adult age between 18 and 60 years and availability of gadolinium-bolused MRV images and pre-/postgadolinium MR images from the same period. Patients with obvious intracranial pathology, such as intracranial masses, hydrocephalus, venous thrombosis, or postsurgical/traumatic derangement of the dural sinuses, and so forth, were excluded. Control patients carried a variety of diagnoses centered on migraine, migraine variants, or headache not otherwise specified.
Table 1: Clinical characteristics of patients with idiopathic intracranial hypertension and controls

\begin{tabular}{lccc}
\hline & $\begin{array}{c}\text { IIH } \\
(\boldsymbol{n}=63)\end{array}$ & $\begin{array}{c}\text { Controls } \\
(\boldsymbol{n}=96)\end{array}$ & $\begin{array}{c}\boldsymbol{P} \\
\text { Value }\end{array}$ \\
\hline Age (mean) (yr) & $31.6 \pm 10.6$ & $35.5 \pm 9.8$ & \\
Female/male & $58: 5$ & $72: 24$ & \\
BMI & $36.5 \pm 8.2$ & $27.5 \pm 6.4$ & $<.0001$ \\
Duration of symptoms & $4.9 \pm 6.8$ & & \\
$\quad$ (mean) (yr) & & & \\
CSF opening pressure & $356.9 \pm 89$ & & \\
$\quad$ (mm $\left.\mathrm{H}_{2} \mathrm{O}\right)$ (mean) & & & \\
\hline Note:-BMl indicates body mass index. & &
\end{tabular}

\section{MR Imaging and MRV Review}

MR and MRV images were reviewed independently of one another. Each case was reviewed independently by 2 neuroradiologists. A randomized list of subjects in each instance was provided to each neuroradiologist in an approximately 50:50 mix of IIH and control cases.

In their review of the MR images, the reviewing neuroradiologists were asked to score each case in a categoric "yes/no" manner for the presence or absence of conventional signs of idiopathic intracranial hypertension. They were also asked to evaluate the coronal T1 postgadolinium images of the TS and decide "yes/no" for whether they perceived a segment of $>50 \%$ stenosis on either side or both sides (Fig 1). Criteria for the diagnosis of TS stenosis included signs of collapse of the sinus on itself, particularly in comparison with more posterior images on the same sequence; signs of herniation of the contour of the brain into the expected location of the sinus ("internal cephalocele"); or clear absence of a definable sinus on $\geq 1$ section.

Review of the MRV sequences was conducted in a similarly blinded, randomized manner. Neuroradiologists were asked to categorically decide whether TS stenosis of $>50 \%$ was present on 1 or both sides. Second, a score for the point of maximal narrowing for each TS was recorded by using a $0-4$ quartile scale (Fig 2). ${ }^{13}$

Finally, the raw data images from each MRV examination in 60 patients with $\mathrm{IIH}$ and the first 40 controls were reviewed for direct measurement of the dimensions of the TS with electronic calipers on the PACS screen. Orthogonal measurements were obtained of the TS, and the cross-sectional area was calculated on the assumption of a roughly triangular configuration of the sinus as (width $\times$ height) / 2. The cross-sectional area of each sinus was calculated in 2 locations. A proximal measurement was performed approximately $1.5 \mathrm{~cm}$ lateral to the torcular when the TS was seen to have assumed a steady horizontal course. A distal measurement was obtained at the point of maximal stenosis. In the absence of a definable stenosis or narrowing, TS measurements were obtained distally at the apex of the upward curve of the TS proximal to the sigmoid sinus.

The interpretation of the MRV examination, reviewed independent of the coronal postgadolinium sequence, was compared with the original clinical interpretation in the electronic records if it was available. Approximately $40 \%$ of the MR imaging/MRV examinations in this study were conducted at a $3 \mathrm{~T}$ magnetic field strength, and the remainder at 1.5T. Postgadolinium comparison T1-weighted imaging was performed by using our routine clinical protocols and consisted of T1-based volumetric acquisitions, 

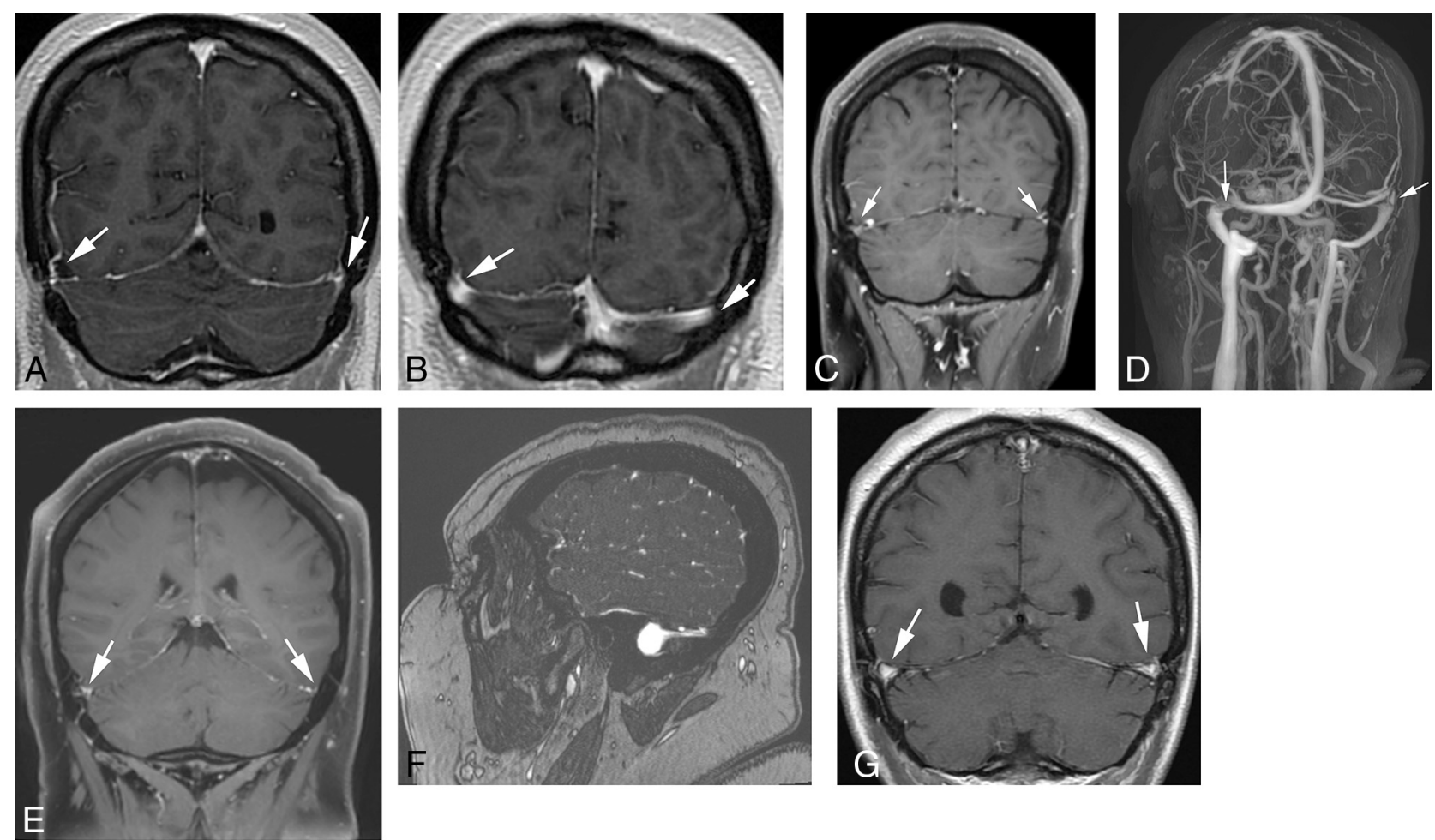

FIG 1. $A-C$, Transverse sinus stenosis on coronal $T 1$ postgadolinium MR imaging. $A$ and $B$, Images from a 43-year-old female patient with idiopathic intracranial hypertension. CSF opening pressure was $380 \mathrm{~mm} \mathrm{H}_{2} \mathrm{O}$. Postgadolinium coronal 3D fast-spoiled gradient recalled images, section thickness $=2.4 \mathrm{~mm}$, demonstrate stenosis of the transverse sinuses bilaterally (arrows). The expected $\Delta$ configuration is distorted and collapsed bilaterally $(A)$. This is more easily appreciated on images from within the same study by comparing with the images of the same sinuses more posteriorly (B). C and $D$, Images from a 36-year-old female patient with IIH. CSF opening pressure was $370 \mathrm{~mm} \mathrm{H}_{2} \mathrm{O}$. Postgadolinium T1-weighted image (C) with coronal reformatting from a 3D acquisition, with a section thickness $=2 \mathrm{~mm}$, TR $=650 \mathrm{~ms}$, TE $=12 \mathrm{~ms}$; and oblique projectional image from a gadolinium-bolused MRV sequence, with TR $=3.83 \mathrm{~ms}$ and TE $=1.39 \mathrm{~ms}$. Stenoses of the transverse sinuses are evident on both images (arrows). E and F, Coronal Tl-weighted image from a 32-year-old female patient with IIH. CSF opening pressure was 304 $\mathrm{mm} \mathrm{H} \mathrm{H}_{2} \mathrm{O}$. Virtually complete collapse of the transverse sinuses can be discerned bilaterally (arrows). A sagittal raw data image $(F)$ from the gadolinium-bolused MRV, section thickness $=0.66 \mathrm{~mm}$, suggests an appearance of herniation of the temporo-occipital tissues into the transverse sinus space. $G$, By contrast, an image from a control patient, a 49-year-old woman with multiple medical problems but no specific explanation for her symptoms of headache. A coronal postgadolinium Tl-weighted image, section thickness $=4 \mathrm{~mm}$, shows the expected $\Delta$ configuration (arrows) of the preserved transverse sinuses bilaterally.

such as sampling perfection with application-optimized contrasts by using different flip angle evolution (SPACE sequence; Siemens, Erlangen, Germany) or CUBE (GE Healthcare, Milwaukee, Wisconsin), fast spin-echo, and conventional spin-echo techniques without and with fat saturation. A few examinations performed at other institutions and included in this study were obtained by using spoiled gradient-recalled or MPRAGE techniques, which are characterized by robust intrasinus signal due to rephasing phenomena. These constituted $<10 \%$ of the studies.

\section{Data Analysis}

Data were stored by using Excel spreadsheets (Microsoft, Redmond, Washington) and were analyzed by using JMP Pro 11.2 for Mac (SAS Institute, Cary, North Carolina). The Student $t$ test was used for comparing the incidence of MR imaging and MRV findings between groups. Ordinate and categoric variables were correlated with continuous variables by using nonparametric statistical procedures, including Wilcoxon/KruskalWallis rank sums, the Pearson correlation coefficient, and the Spearman $\rho$.

\section{RESULTS}

\section{Subjects}

Patients with IIH and control subjects were similar in overall profile (Table 1). Patients with IIH had a slightly greater preponderance of women and a higher body mass index than control subjects.

\section{MR Imaging Interpretation}

Bilateral TS stenosis was discerned in $83 \%$ of patients with IIH with the coronal postgadolinium T1-weighted images and in $7 \%$ of controls $(P<.0001)$ (Table 2$)$. The nature of the TS stenosis was often a collapse or flattening of the expected contours of the dural sinus. However, $50 \%$ of subjects demonstrated a uni- or bilateral pattern of effective herniation of temporo-occipital tissue into the expected location of the sinus, with the margins being presumably constrained by the bony edges of the dural sinus along the inner calvaria. This appearance is referred to as "an internal cephalocele" by the authors. Unilateral TS stenosis or hypoplasia was perceived in an additional $9 \%$ of controls. Other MR imaging signs of IIH were seen with less sensitivity. Signs of an "empty sella" were discerned in 53\% of patients with $\mathrm{IIH}$ and 5\% 


\section{Degrees of Patency}
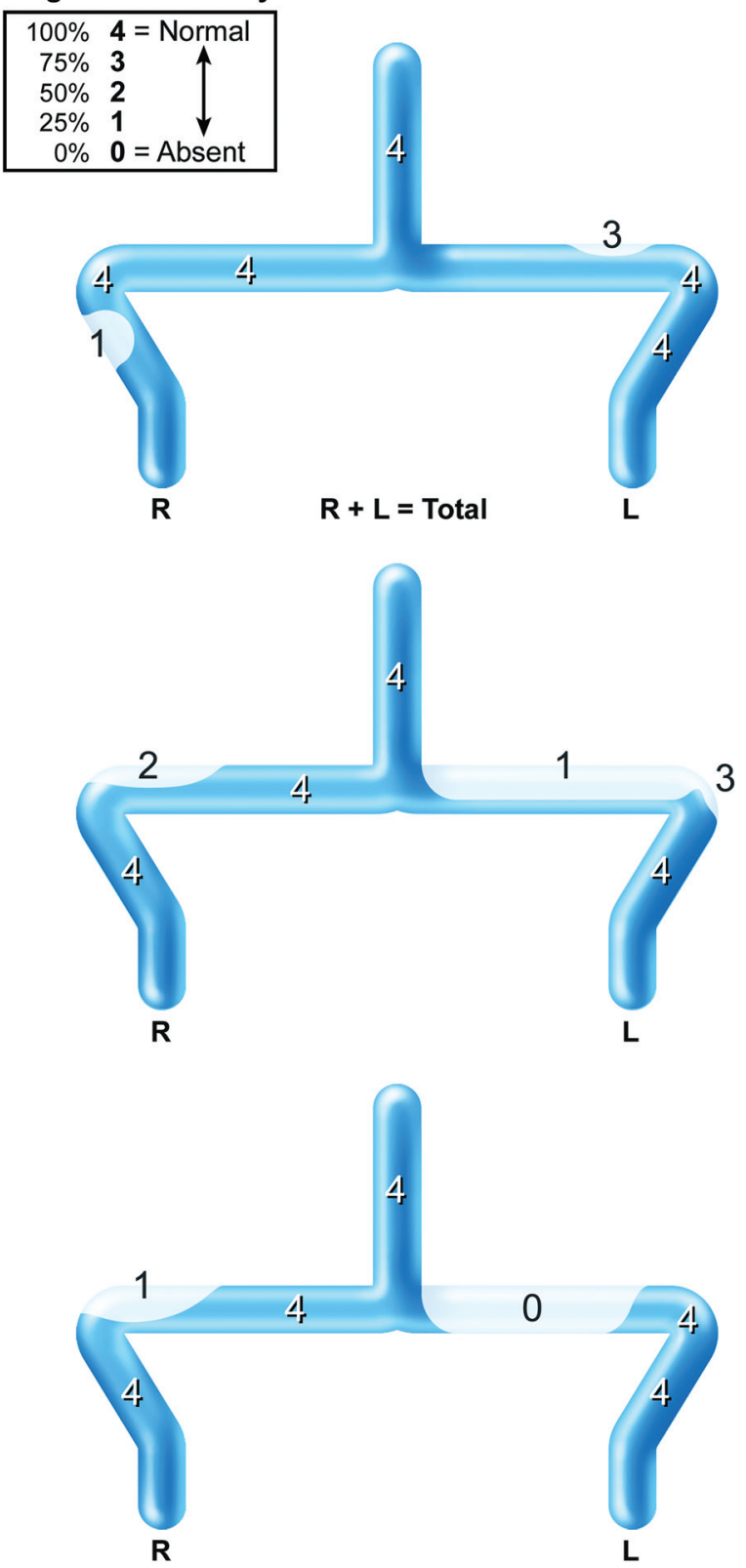

FIG 2. Schema for scoring transverse sinus patency based on Farb et al (2003)..$^{13}$ Transverse sinuses were rated by using the MRV, MIP, and raw data images on a 5-point scale bilaterally between 0 (absent) and 4 (full expected contour of a normally sized transverse sinus). The scoring system does not discern etiologies of the narrowing, merely the degree of patency/stenosis on each side. A maximum possible score of 8 would, therefore, indicate full patency on each side. $R$ indicates right; L, left.

of controls. Optic nerve sheath distension ( $>6 \mathrm{~mm}$ in transverse dimensions) was seen in $63 \%$ of patients with $\mathrm{IIH}$ and $4 \%$ of controls. Papilledema and DWI changes were less frequent (Table 2).

\section{MRV Interpretation}

Bilateral TS stenosis of $>50 \%$ was perceived categorically in $94 \%$ of patients with IIH compared with $3 \%$ of controls $(P<.0001)$. When we compared the quartile scores of the configuration of the TS bilaterally (left + right score; maximum, 8), patients with IIH
Table 2: Results-MRI findings, interpreted independently of MRV findings

\begin{tabular}{lcc}
\hline \multicolumn{1}{c}{ Retrospective Study Interpretation } & $\begin{array}{c}\text { IIH } \\
(\boldsymbol{n}=63)\end{array}$ & $\begin{array}{c}\text { Controls } \\
(\boldsymbol{n}=96)\end{array}$ \\
\hline Empty sella & $34(53 \%)$ & $5(5 \%)$ \\
Dilated optic nerve sheath of $>6 \mathrm{~mm}$ & $40(63 \%)$ & $4(4 \%)$ \\
DWI bright spot at fundus & $6(9 \%)$ & $1(1 \%)$ \\
Papilledema & $20(34 \%)$ & $4(4 \%)$ \\
$\begin{array}{l}\text { Bilateral TS stenosis on coronal T2 } \\
\quad \text { post gadolinium }\end{array}$ & $53(83 \%)$ & $7(7 \%)$ \\
$\begin{array}{l}\text { Internal cephalocele into the transverse } \\
\text { sinus }\end{array}$ & $32(50 \%)$ & 0 \\
\hline
\end{tabular}

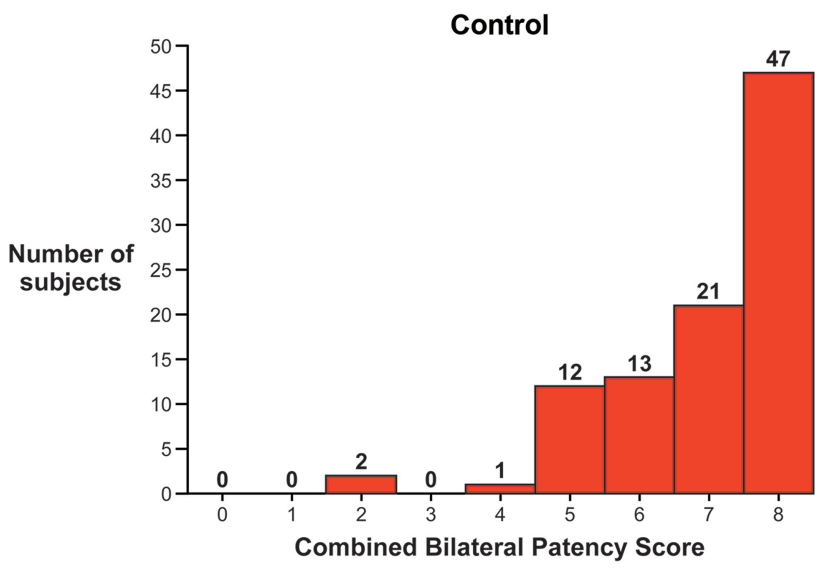

Idiopathic Intracranial Hypertension

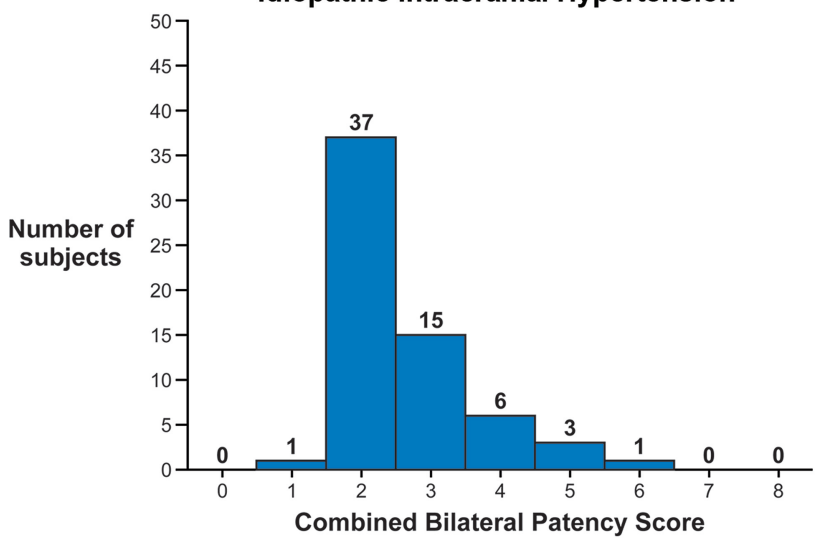

FIG 3. Patency scores on MRV interpretation. A summation of left and right patency scores, maximal normal $=8$, was performed on the blinded readings of the MRV images independent of clinical data or the MR imaging appearance. The scatter of scores shows a clear discernment between patients with $\mathrm{IIH}$ and controls. Almost all controls scored $\geq 5$, while patients with $\mathrm{IIH}$ almost all scored $\leq 5$.

scored almost exclusively $<5$ and were thus discernible from controls, who almost all scored $\geq 5(P<.0001)$ (Fig 3$)$.

\section{MRV Cross-Sectional Area Measurements}

Calculation of the narrowed distal segment of the TS in patients with IIH showed a substantial reduction compared with controls measured in the same location (Table 3). The left and right distal transverse sinus showed an $88 \%$ and $86 \%$ reduction in mean cross-sectional area, respectively, in patients with IIH compared with controls. The summation of the left and right total outflow cross-sectional area was similarly affected. A lesser degree of sinus narrowing was detectable on statistical analysis more posteriorly 
Table 3: Results-MRV cross-sectional area measurements on transverse sinuses

\begin{tabular}{lcccccc}
\hline & $\begin{array}{c}\text { Left TS Proximal } \\
\left(\text { Mean) }\left(\mathbf{m m}^{2}\right)\right.\end{array}$ & $\begin{array}{c}\text { Left TS } \\
\text { Distal }\end{array}$ & $\begin{array}{c}\text { Right TS } \\
\text { Proximal }\end{array}$ & $\begin{array}{c}\text { Right TS } \\
\text { Distal }\end{array}$ & $\begin{array}{c}\text { Left + Right } \\
\text { Proximal }\end{array}$ & $\begin{array}{c}\text { Left + Right } \\
\text { Distal }\end{array}$ \\
\hline Controls & $24.7 \pm 14.1$ & $23.9 \pm 10.7$ & $37.5 \pm 15.9$ & $29.9 \pm 11.4$ & $62.2 \pm 19.3$ & $53.8 \pm 15.4$ \\
IIH & $19.2 \pm 13.3$ & $2.9 \pm 2.1$ & $28.4 \pm 14.2$ & $4.1 \pm 4.1$ & $47.5 \pm 2.4$ & $7.1 \pm 4.8$ \\
$P$ value (1-way ANOVA) & NS & .0001 & .0003 & .0001 & .0001 & .0001 \\
\hline
\end{tabular}

Note:-NS indicates not significant.

in the sinuses, particularly on the right side. However, the proximal effect was less evident visually in individual cases.

\section{Correlation and Multivariate Analysis}

Analysis of the correlation among the MR imaging observations, the MRV interpretation, and the direct measurement of the TS dimensions showed strong consistency, indicating that the reviewers' perceptions of MR imaging findings of TS stenosis were valid. Correlation with the Spearman $\rho$ between the MR imaging interpretation of categoric TS patency/stenosis on the one hand and the MRV grading scale on the other showed a highly significant correspondence for all subjects $(P<.0001)$. Despite some statistical groups being small in the subanalysis (eg, few patients with IIH had normal-appearing sinuses), this statistical robustness held up in the analysis by diagnostic group (controls, $P<$ .002; IIH group, $P<.028$ ).

Similarly, the validity of the reviewers' interpretation of the coronal MR images was upheld by the correlation between the MR imaging diagnosis of TS stenosis and the direct measurement of the cross-sectional area of the TS (Spearman $\rho=-.7504, P<$ .0001).

\section{Comparison with Original Clinical Reports}

Many of the subjects with IIH in this group were imaged with a variety of MR imaging and MRV studies during the time course of this retrospective review, including studies from outside institutions. Approximately 33\% of subjects with IIH had at least 1 earlier MRV interpretation, which the reviewers in this study would have retrospectively revised. Findings of TS narrowing or stenosis documented in this study were previously ascribed on $\geq 1$ occasion in 33\% of this patient group to "hypoplasia," "arachnoid granulations," or "anatomic variability in the absence of other signs of idiopathic intracranial hypertension.”

\section{DISCUSSION}

Idiopathic intracranial hypertension is a poorly understood condition, the hallmark of which is elevation of CSF opening pressure without an identifiable intracranial mass or ventriculomegaly. ${ }^{1,15-17}$ It shares many similarities with a condition of visual impairment and intracranial pressure observed in astronauts after prolonged exposure to conditions of microgravity. ${ }^{18-20}$ It may also share common pathophysiologic pathways with acute mountain sickness, a condition in which recent MR imaging studies have focused on alterations of arterial inflow, cerebral white matter diffusivity, and venous outflow restriction. ${ }^{21}$ Explanations for the mechanisms underlying IIH have focused on overproduction of CSF; impaired resorption of $\mathrm{CSF}^{22}$; dysautoregulation of cerebral blood flow ${ }^{23}$; dysregulation of fluid homeostasis, among others, in turn mediated by underlying endocrinopathies; fluid and electrolyte shifts with subtle white matter edema ${ }^{24}$; dysregulation of aquaporin 1 and aquaporin 4 receptors ${ }^{16,25,26}$; or proinflammatory states ${ }^{27,28}$ due to mitochondrial dysregulation or circulating signaling leptins. ${ }^{29-32}$

A preponderance of evidence suggests a high incidence of IIH in women of childbearing age with an elevated body mass index, supporting hypotheses that metabolic or hormonal factors may play a strong role. ${ }^{2,3}$ However, evidence supporting a single etiologic sequence of pathophysiology has not been consistent. Some volumetric studies have suggested alterations of CSF volume or brain volume as the explanation for elevated acranial pressure. $^{33-35}$ Studies of cerebral perfusion by using xenon-enhanced CT, MR perfusion, and SPECT have not identified a consistent pattern of hyperperfusion or hypoperfusion. ${ }^{36,37}$ Since the observation that stenoses of the transverse sinuses are seen in $94 \%$ of patients with $\mathrm{IIH},{ }^{13,14,38}$ speculation has been raised that venous outflow obstruction could play a role in the genesis of $\mathrm{IIH},{ }^{39}$ but reversibility of this finding with effective medical therapy and reduction of intracranial pressure suggests that venous occlusive findings are secondary to the elevated intracranial pressure and not vice versa. ${ }^{40-42}$

Secondary effects of chronically elevated acranial pressure from any cause include optic nerve sheath distension, papilledema, flattening of the posterior globe, and flattening and depression of the diaphragma sellae. These secondary effects determine the structural alterations that may be detectable on imaging studies in patients with IIH on which neuroradiologists rely to make this diagnosis. Long-established MR imaging signs of IIH include optic nerve sheath distension, ${ }^{12,43,44}$ empty sella appearance, ${ }^{44,45}$ enhancement of the vessels at the optic papilla, ${ }^{12,43,44,46-48}$ meningocele formation, ${ }^{49}$ or restriction of diffusion at the optic nerve head. ${ }^{50}$ However, the sensitivity of these MR imaging signs in patients with $\mathrm{IIH}$ varies widely between studies, with reported rates of between $6 \%$ and $72 \% .{ }^{51} \mathrm{MR}$ imaging studies in pediatric patients in whom anesthesia helps to eliminate eye motion show greater sensitivity to ocular findings of $\mathrm{IIH}$, with optic nerve sheath distension seen in $88 \%$ of pediatric patients in 1 study. ${ }^{52}$ Generally, sensitivity rates in adult studies tend to be substantially lower with greater published emphasis on the specificity of these findings. The issue of specificity of the finding of TS stenosis is not addressed in this article due to the selective nature of the control population, mostly presenting with nonspecific headache conditions. The utility of the MR imaging/MRV signs we describe in patients with IIH lies in their sensitivity in allowing the neuroradiologist to alert the treating clinician to what may have been previously an overlooked or unsuspected diagnosis.

More useful may be the effect of sustained intracranial hypertension on the transverse dural sinuses. Farb et $\mathrm{al}^{13}$ reported that stenosis of the transverse sinuses on gadolinium-bolused MR venography is detectable in $94 \%$ of patients with $\mathrm{IIH}$, making this 
a more sensitive diagnostic indicator in adults than previously established MR imaging signs. However, in most instances when a patient with IIH is imaged, an MRV sequence will not be included with the study unless the diagnosis of IIH is strongly suspected in advance and a specific request for an MRV has been submitted. Therefore, it seems reasonable to conclude that without an MRV sequence being available in most instances, neuroradiologic sensitivity to the diagnosis of IIH will be limited. Furthermore, even when an MRV sequence has been obtained, the nature of transverse sinus narrowing in some patients may seem nonspecific when consideration is given to entities such as anatomic asymmetry, indentations in the contrast column due to arachnoid granulations, or sequelae of previous episodes of dural sinus thrombosis. In this retrospective study, potentially helpful findings in 33\% of the MRV sequences in patients with IIH were downplayed or dismissed in $\geq 1$ of the original clinical radiology reports. It might be conjectured that the significance of observations of transverse sinus narrowing was downplayed by the original interpreting radiologist because of the absence of other more "established" signs of idiopathic intracranial hypertension, but our study was not constructed to examine this particular question. We surmise that the diagnosis of IIH on neuroradiologic interpretation may be thus stymied on 2 levels: First, when an MRV sequence is not available, the neuroradiologist is at a disadvantage in not having the most consistent anatomic correlate of IIH demonstrated to best advantage (ie, MRV signs of TS stenosis). Second, when an MRV is available, findings of TS stenosis may be confused with perceptions of anatomic variability and asymmetry and so forth.

We acknowledge that our study is limited in several respects, including its retrospective nature. Our IIH group was carefully screened and diagnosed by using the Modified Dandy Criteria and, as such, represents one of the largest cohorts in this field of publication. However, our control group was of a more heterogeneous composition, mostly diagnosed with migraine or migrainevariant headache. As we retrospectively reviewed the clinical notes, it appeared conceivable that this control group may even contain a number of patients with undiagnosed idiopathic intracranial hypertension. Although this is partially conjectural on our part, it could form an explanation for why a small number (3\%) of the controls demonstrated bilateral TS stenosis. Moreover, the observation in this study that a small number of controls demonstrated unilateral or bilateral TS stenosis is consistent with previous authors' experiences. The control group described by Farb et $\mathrm{al}^{13}$ demonstrated a $6.7 \%$ rate of bilateral TS narrowing, while Ayanzen et $\mathrm{al}^{53}$ found that $31 \%$ of patients with normal MR imaging findings showed substantial flow gaps in the TS on MRV. Similar rates of TS interruptions were reported by Bono et $\mathrm{al}^{54}$ in a population of patients with normal CSF pressures who presented with a variety of headache and psychiatric diagnoses. The MRV and MR imaging techniques used in our study also varied and evolved during the 5 years of retrospective review, with images with a variety of section thicknesses $(2-5 \mathrm{~mm})$, T1-based techniques, and 1.5 and $3 \mathrm{~T}$ scanners. However, we believe that these methodologic shortcomings do not detract substantively from our observations pertaining to the core IIH cohort.

\section{CONCLUSIONS}

Our retrospective study is consistent with previous imaging studies of idiopathic intracranial hypertension and demonstrates that TS stenosis/collapse is the most consistent anatomic finding in a group of patients with this condition. Our findings of a $93 \%$ incidence of TS stenosis on MRV in this group of patients replicates those of previous studies. ${ }^{13,14,38}$ More useful, however, is that we have demonstrated that more careful scrutiny of the appearance of the transverse sinuses on coronal $\mathrm{T} 1$ postgadolinium imaging can help neuroradiologists almost completely compensate for the handicap of not having an MRV sequence on hand in this patient group. Additionally, our study suggests that neuroradiologists may need to be more critical in the degree of latitude they exercise in the interpretation of TS narrowing as anatomic variability. The absence of alternative MR imaging signs of IIH in TS narrowing should not deter the neuroradiologist from giving strong consideration to this diagnosis in the appropriate clinical setting.

\section{REFERENCES}

1. Friedman DI, Liu GT, Digre KB. Revised diagnostic criteria for the pseudotumor cerebri syndrome in adults and children. Neurology 2013;81:1159-65 CrossRef Medline

2. Daniels AB, Liu GT, Volpe NJ, et al. Profiles of obesity, weight gain, and quality of life in idiopathic intracranial hypertension (pseudotumor cerebri). Am J Ophthalmol 2007;143:635-41 CrossRef Medline

3. Ko MW, Chang SC, Ridha MA, et al. Weight gain and recurrence in idiopathic intracranial hypertension: a case-control study. Neurology 2011;76:1564-67 CrossRef Medline

4. Fraser JA, Bruce BB, Rucker J, et al. Risk factors for idiopathic intracranial hypertension in men: a case-control study. J Neurol Sci 2010; 290:86-89 CrossRef Medline

5. Thurtell MJ, Trotti LM, Bixler EO, et al. Obstructive sleep apnea in idiopathic intracranial hypertension: comparison with matched population data. J Neurol 2013;260:1748-51 CrossRef Medline

6. Wall M, Purvin V. Idiopathic intracranial hypertension in men and the relationship to sleep apnea. Neurology 2009;72:300-01 CrossRef Medline

7. Wardly DE. Intracranial hypertension associated with obstructive sleep apnea: a discussion of potential etiologic factors. Med Hypotheses 2014;83:792-97 CrossRef Medline

8. Soelberg Sørensen P, Gjerris F, Svenstrup B. Endocrine studies in patients with pseudotumor cerebri: estrogen levels in blood and cerebrospinal fluid. Arch Neurol 1986;43:902-06 CrossRef Medline

9. Tabassi A, Salmasi AH, Jalali M. Serum and CSF vitamin A concentrations in idiopathic intracranial hypertension. Neurology 2005;64: 1893-96 CrossRef Medline

10. Warner JE, Larson AJ, Bhosale P, et al. Retinol-binding protein and retinol analysis in cerebrospinal fluid and serum of patients with and without idiopathic intracranial hypertension. J Neuroophthalmol 2007;27:258-62 CrossRef Medline

11. Cinciripini GS, Donahue S, Borchert MS. Idiopathic intracranial hypertension in prepubertal pediatric patients: characteristics, treatment, and outcome. Am J Ophthalmol 1999;127:178-82 CrossRef Medline

12. Maralani PJ, Hassanlou M, Torres C, et al. Accuracy of brain imaging in the diagnosis of idiopathic intracranial hypertension. Clin Radiol 2012;67:656-63 CrossRef Medline

13. Farb RI, Vanek I, Scott JN, et al. Idiopathic intracranial hypertension: the prevalence and morphology of sinovenous stenosis. Neurology 2003;60:1418-24 CrossRef Medline

14. Higgins JN, Gillard JH, Owler BK, et al. MR venography in idiopathic intracranial hypertension: unappreciated and misunderstood. J Neurol Neurosurg Psychiatry 2004;75:621-25 CrossRef Medline 
15. Friedman DI, Jacobson DM. Diagnostic criteria for idiopathic intracranial hypertension. Neurology 2002;59:1492-95 CrossRef Medline

16. Baykan B, Ekizoğlu E, Altıkka Uzun G. An update on the pathophysiology of idiopathic intracranial hypertension alias pseudotumor cerebri. Agri 2015;27:63-72 CrossRef Medline

17. Ducros A, Biousse V. Headache arising from idiopathic changes in CSF pressure. Lancet Neurol 2015;14:655-68 CrossRef Medline

18. Wilson $\mathrm{MH}$, Imray $\mathrm{CH}$, Hargens $\mathrm{AR}$. The headache of high altitude and microgravity: similarities with clinical syndromes of cerebral venous hypertension. High Alt Med Biol 2011;12:379-86 CrossRef Medline

19. Wilson $\mathrm{MH}$, Wright $\mathrm{A}$, Imray $\mathrm{CH}$. Intracranial pressure at altitude. High Alt Med Biol 2014;15:123-32 CrossRef Medline

20. Nelson ES, Mulugeta L, Myers JG. Microgravity-induced fluid shift and ophthalmic changes. Life (Basel) 2014;4:621-65 CrossRef Medline

21. Sagoo RS, Hutchinson CE, Wright A, et al; Birmingham Medical Research and Expedition Society. Magnetic resonance investigation into the mechanisms involved in the development of high-altitude cerebral edema. J Cereb Blood Flow Metab 2017;37:319-31 CrossRef Medline

22. Chazal J, Janny P, Georget AM, et al. Benign intracranial hypertension: a clinical evaluation of the CSF absorption mechanisms. Acta Neurochir Suppl (Wien) 1979;28:505-08 Medline

23. Bateman GA. Idiopathic intracranial hypertension: priapism of the brain? Med Hypotheses 2004;63:549-52 CrossRef Medline

24. Moser FG, Hilal SK, Abrams G, et al. MR imaging of pseudotumor cerebri. AJR Am J Roentgenol 1988;150:903-09 CrossRef Medline

25. King LS, Nielsen S, Agre P. Aquaporin-1 water channel protein in lung: ontogeny, steroid-induced expression, and distribution in rat. J Clin Invest 1996;97:2183-91 CrossRef Medline

26. Zador Z, Bloch $\mathrm{O}$, Yao $\mathrm{X}$, et al. Aquaporins: role in cerebral edema and brain water balance. Prog Brain Res 2007;161:185-94 CrossRef Medline

27. Sinclair AJ, Ball AK, Burdon MA, et al. Exploring the pathogenesis of IIH: an inflammatory perspective. J Neuroimmunol 2008;201-02: 212-20 CrossRef Medline

28. Skau M, Brennum J, Gjerris F, et al. What is new about idiopathic intracranial hypertension? An updated review of mechanism and treatment. Cephalalgia 2006;26:384-99 CrossRef Medline

29. Dhungana S, Sharrack B, Woodroofe N. Cytokines and chemokines in idiopathic intracranial hypertension. Headache 2009;49:282-85 CrossRef Medline

30. Lampl Y, Eshel Y, Kessler A, et al. Serum leptin level in women with idiopathic intracranial hypertension. J Neurol Neurosurg Psychiatry 2002;72:642-43 CrossRef Medline

31. Samancı B, Samancı Y, Tüzün E, et al. Evidence for potential involvement of pro-inflammatory adipokines in the pathogenesis of idiopathic intracranial hypertension. Cephalalgia 2016 May 18. [Epub ahead of print] Medline

32. Sheldon CA, Kwon YJ, Liu GT, et al. An integrated mechanism of pediatric pseudotumor cerebri syndrome: evidence of bioenergetic and hormonal regulation of cerebrospinal fluid dynamics. Pediatr Res 2015;77:282-89 CrossRef Medline

33. Joynt RJ, Sahs AL. Brain swelling of unknown cause. Neurology 1956; 6:801-03 Medline

34. Johnston I. Reduced C.S.F. absorption syndrome: reappraisal of benign intracranial hypertension and related conditions. Lancet 1973; 2:418-21 Medline

35. Malm J, Kristensen B, Markgren P, et al. CSF hydrodynamics in idiopathic intracranial hypertension: a long-term study. Neurology 1992;42:851-58 CrossRef Medline
36. Bicakci K, Bicakci S, Aksungur E. Perfusion and diffusion magnetic resonance imaging in idiopathic intracranial hypertension. Acta Neurol Scand 2006;114:193-97 CrossRef Medline

37. Lorberboym M, Lampl Y, Kesler A, et al. Benign intracranial hypertension: correlation of cerebral blood flow with disease severity. Clin Neurol Neurosurg 2001;103:33-36 CrossRef Medline

38. Sander K, Poppert H, Etgen T, et al. Dynamics of intracranial venous flow patterns in patients with idiopathic intracranial hypertension. Eur Neurol 2011;66:334-38 CrossRef Medline

39. Woodall MN, Nguyen KD, Alleyne $\mathrm{CH}$ Jr, et al. Bilateral transverse sinus stenosis causing intracranial hypertension. BMJ Case Rep 2013;2013 CrossRef

40. Rohr A, Dorner L, Stingele R, et al. Reversibility of venous sinus obstruction in idiopathic intracranial hypertension. AJNR Am J Neuroradiol 2007;28:656-59 Medline

41. King JO, Mitchell PJ, Thomson KR, et al. Cerebral venography and manometry in idiopathic intracranial hypertension. Neurology 1995;45:2224-28 CrossRef Medline

42. Fraser JA, Leung AE. Reversibility of MRI features of pseudotumor cerebri syndrome. Can J Neurol Sci 2014;41:530-32 CrossRef Medline

43. Agid R, Farb RI, Willinsky RA, et al. Idiopathic intracranial hypertension: the validity of cross-sectional neuroimaging signs. Neuroradiology 2006;48:521-27 CrossRef Medline

44. Ridha MA, Saindane AM, Bruce BB, et al. Magnetic resonance imaging findings of elevated intracranial pressure in cerebral venous thrombosis versus idiopathic intracranial hypertension with transverse sinus stenosis. Neuroophthalmology 2013;37:1-6 CrossRef Medline

45. Yuh WT, Zhu M, Taoka T, et al. MR imaging of pituitary morphology in idiopathic intracranial hypertension. J Magn Reson Imaging 2000;12:808-13 Medline

46. Brodsky MC, Vaphiades M. Magnetic resonance imaging in pseudotumor cerebri. Ophthalmology 1998;105:1686-93 CrossRef Medline

47. Butros SR, Goncalves LF, Thompson D, et al. Imaging features of idiopathic intracranial hypertension, including a new finding: widening of the foramen ovale. Acta Radiol 2012;53:682-88 CrossRef Medline

48. Saindane AM, Bruce BB, Riggeal BD, et al. Association of MRI findings and visual outcome in idiopathic intracranial hypertension. AJR Am J Roentgenol 2013;201:412-18 CrossRef Medline

49. Lloyd KM, DelGaudio JM, Hudgins PA. Imaging of skull base cerebrospinal fluid leaks in adults. Radiology 2008;248:725-36 CrossRef Medline

50. Salvay DM, Padhye LV, Huecker JB, et al. Correlation between papilledema grade and diffusion-weighted magnetic resonance imaging in idiopathic intracranial hypertension. J Neuroophthalmol 2014;34:331-35 CrossRef Medline

51. Bidot S, Saindane AM, Peragallo JH, et al. Brain imaging in idiopathic intracranial hypertension. J Neuroophthalmol 2015;35: 400-11 CrossRef Medline

52. Görkem SB, Doğanay S, Canpolat M, et al. MR imaging findings in children with pseudotumor cerebri and comparison with healthy controls. Childs Nerv Syst 2015;31:373-80 CrossRef Medline

53. Ayanzen RH, Bird CR, Keller PJ, et al. Cerebral MR venography: normal anatomy and potential diagnostic pitfalls. AJNR Am J Neuroradiol 2000;21:74-78 Medline

54. Bono F, Lupo MR, Lavano A, et al. Cerebral MR venography of transverse sinuses in subjects with normal CSF pressure. Neurology 2003;61:1267-70 CrossRef Medline 